\title{
КАДМИЙ И СВИНЕЦ В ИЛАХ РЕКИ УРАЛ: ВАЛОВОЕ СОДЕРЖАНИЕ И РАСПРЕДЕЛЕНИЕ
}

\section{CADMIUM AND LEAD IN SLUDGE DEPOSITS URAL RIVERS: GROSS CONTENT, DISTRIBUTION AND ENRICHMENT}

\section{G. Solovykh \\ E. Shostak \\ T. Osinkina}

Summary. Purpose: analysis of silt deposits in the middle reaches of the Ural River for the presence of cadmium and lead, the distribution of these metals and the level of pollution of the river (by enrichment factors).

Methods: determination of the gross content of cadmium and lead in bottom sludge was carried out by atomic absorption spectrophotometry. The level of contamination of bottom sediments was identified by the enrichment factor, which is a value equal to the ratio of the content of heavy metal in bottom sediments $(\mathrm{mg} / \mathrm{kg}$ ) to the value of the metal clarke in the lithosphere $(\mathrm{mg} / \mathrm{kg})$.

Results: the total content and level of contamination of silts of some sections of the middle reaches of the Ural River with cadmium and lead were studied. An uneven distribution of pollutants in bottom sediments has been established, despite the lenticular (fluid) nature of the reservoir. According to the enrichment factor (KO), the sites with the highest (for cadmium the Ural river - above the city of Orsk (KO $=1.64)$, for lead the Ural river - Treatment facilities $(K 0=103.1)$ ) and the smallest (for cadmium the Ural river - Water intake $(K 0=0.42)$, for lead from the Ural River - Camp“Dubki” (KO=31.9)) levels of metal pollution.

Conclusions: cadmium and lead are present in the silts of all study areas of the Ural River, which indicates the presence of natural or anthropogenic sources of these metals with different mobility. The accumulation of toxicants in the ecotopes of the river is uneven, which may be due to differences in the structure and properties of silt deposits, the nature of the river flow, and the unevenness of its average annual and interannual runoff.

Keywords: heavy metals, pollutants, environmental standard, enrichment factor, gross content, level of pollution, accumulation, toxicity, complexing ability.
Соловых Галина Николаевна

Д.б.н., ФГБОУ ВО «Оренбургский государственный медицинский университет» Министерства здравоохранения Российской Федерации»

k_biology@orgma.ru

Шостак Елена Ивановна

К.б.н., дочент, ФГБОУ ВО «Оренбургский государственный медицинский университет» Министерства здравоохранения Российской

Федерации»

Осинкина Татьяна Владимировна

К.б.н., старший преподаватель, ФГБОУ ВО «Оренбургский государственный медицинский университет» Министерства здравоохранения Российской Федерации» osinkina12@mail.ru

Аннотация. Цель: анализ иловых отложений среднего течения реки Урал на наличие кадмия и свинца, распределения указанных металлов и уровень загрязнённости реки (по коэффициентам обогащения).

Методы: определение валового содержания кадмия и свинца в донных илах проводили методом атомно-абсорбционной спектрофотометрии. Уровнь загрязнённости донных отложений выявляли по коэффициенту обогащения, который представляет собой величину равную отношению содержания тяжёлого металла в донных отложениях (мг/кг) к величине кларка металла в литосфере (мг/кг).

Результаты: изучено валовое содержание и уровень загрязнённости илов некоторых участков среднего течения реки Урал кадмием и свинцом. Установлено неравномерное распределение поллютантов в донных отложениях, несмотря на лентический (текучий) характер водоёма. По коэффициенту обогащения (КО) определены участки с наибольшим (по кадмию река Урал — выше города Орска (KO = 1,64), по свинцу река Урал — Очистные сооружения $(K 0=103,1))$ и наименьшим (по кадмию река Урал — Водозабор $(К 0=0,42)$, по свинцу река Урал — лагерь «Дубки» $(K 0=31,9))$ уровнями загрязнения металлами.

Выводы: кадмий и свинец присутствуют в илах всех участков исследования реки Урал, что свидетельствует о наличии природных или антропогенных источников различных по подвижности форм данных металлов. Аккумуляция токсикантов в экотопах реки неравномерна, что может быть обусловлено различиями в структуре и свойствах иловых отложений, характере течения реки, неравномерности её среднегодового и межгодового стока.

Ключевые слова: тяжёлые металлы, поллютанты, экологический норматив, коэффициент обогащения, валовое содержание, уровень загрязнённости, аккумуляция, токсичность, комплексообразующая способность. 


\section{Введение}

$\Pi$ о биологической классификации химических элементов к тяжёлым металлам относятся микрои ультрамикроэлементы, которые при значительном накоплении в окружающей среде проявляют свойства токсикантов и экотоксикантов [1, с. 45]. Вероятными токсикантами следует считать соединения элементов, оказывающие негативное действие (часто пролонгированного характера) на отдельный организм, группу организмов, вид или некоторую определённую совокупность видов; экотоксиканты как правило воздействуют сочетанно на экосистему в целом [6, с. 34].

\section{Материалы и методы исследования}

Материалами исследования явились вода и иловые отложения (донные илы), отобранные с 18 участков об-

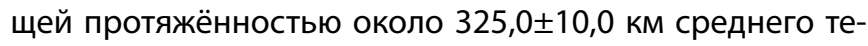
чения реки Урал.

Отбор воды осуществляли на участках исследования с помощью батометра на расстоянии не менее 2-х метров от берега в ёмкости из тёмного стекла с плотными крышками и хранили при температуре $-18^{\circ} \mathrm{C}$ до отправки в лабораторию для последующего исследования. Забор донных (иловых) отложений - верхнего 10-15- сантиметрового слоя грунта на дне водоёма проводили с использованием совка-скребка, упаковывали в ёмкости из тёмного стекла с плотными крышками и хранили при температуре $-18^{\circ} \mathrm{C}$ до отправки в лабораторию для последующего исследования.

Определение валового содержания кадмия и свинца в донных илах проводили на базе лаборатории ФГБУ ГЦ Агрохимической службы «Оренбургский», методом атомно-абсорбционной спектрофотометрии на приборе «Спектр-5-3» в соответствие с методическими указаниями М.ЦИНАО, 1992 (для донных отложений).

Анализ уровня загрязнённости донных отложений кадмием и свинцом проводили по коэффициенту обогащения, который представляет собой величину равную отношению содержания тяжёлого металла в донных отложениях (мг/кг) к величине кларка металла в литосфере (мг/кг): $\mathrm{KO}_{\partial o}=[\mathrm{TM}]_{\partial o} /[\mathrm{TM}]_{\kappa л}$. Среднее содержание в литосфере (кларк) кадмия составляет 0,13 мг/кг, для свинца 0,16 мг/кг [3, с. 76; 12, с. 323].

\section{^итературный обзор}

Металлы с атомной массой более 50, отличаются способностью к аккумуляции в объектах природной среды и оказывают, как правило, множественное влияние на экосистему [2, с. 78; 4, с. 23]. Сформирована опреде- ленная группа химических элементов, в которую входят кадмий, медь, мышьяк, никель, ртуть, свинец и хром как опасные для здоровья человека и большинства других живых организмов [5, с. 6; 8, с. 86]. К числу высокотоксичных относятся кадмий, свинец, ртуть и их соединения [10, с. 72; 15, с. 44]. Кадмий губителен для живых организмов даже в микроконцентрациях: для человека уже 10 мкг/сутки крайне токсичны. Опасность усугубляется ещё и тем, что интоксикация может прогрессировать даже после прекращения контакта с кадмием или его соединениями [7, с. 43; 9, с. 121]. Свинец по степени токсичности стоит после таллия, ртути и кадмия [11, с. 49]. Отравления свинцом чаще всего носят затяжной хронический характер со значительным угнетением работы нервной, соединительной и костной тканей $[16$, с. 12].

Ведомственными организациями и экспертами по охране окружающей среды на основе детального анализа многочисленных общих и биомониторинговых исследований среди металлов, обладающих токсическим действием, выделена особая группа в которую включены элементы: медь, мышьяк, никель, ртуть, свинец, цинк, хром и их соединения как наиболее опасные для жизнедеятельности и динамики обмена веществ человека и животных [5, с. 25]. Чистые вещества и соединения кадмия, свинца и ртути определены из них как наиболее токсичные [7, с. 31].

Негативный характер действия на живые организмы указанной группы металлов обусловлен, как правило, рядом отличительных физико-химических свойств:

1. Повышенной способностью к комплексообразованию, обуславливающей формирование в почвах и донных отложениях устойчивых металлоорганических соединений хелатного типа, снижающих скорость выведения металлов из экосистемы;

2. Повышенной липофильностью, позволяющей быстро проникать через плазмалеммы клеток тканей организмов и связываться с активными центрами ферментов, изменяя их активность, и, таким образом, нарушать обмен веществ;

3. Высокой подвижностью ряда их металлоорганических соединений (в определённых условиях) которая позволяет данной группе поллютантов лишь перераспределяться между компонентами природной среды и долгое время циркулировать по трофическим цепям, аккумулируясь в последних звеньях трофических уровней.

Таким образом, некоторые физико-химические особенности указанных металлов, во многом определяют их повышенную токсичность. Однако, широкая область применения данных металлов в различных отраслях промышленности Оренбургской области и факт обнаружения кадмия и свинца в воде и водной вытяжки донных отложений ранее проведёнными мониторинговыми 
p. Урал - Чернореченский мост

p. Урал - лагерь "Чайка"

р. Урал - Очистные сооружения p. Урал - Железнодорожный мост

р. Урал - Автодорожный мост р. Урал - Водозабор р. Урал - лагерь "Дубки" p. Урал - Карьер р. Урал - т/б Прогресс р. Урал - с. Красногор

р. Урал - с. Алабайтал

р. Урал - с. Никольское p. Урал - ниже г. Новотроицка р. Урал - выше г. Новотроицка р. Урал - в черте г. Орска

р. Урал - выше г. Орска р. Урал - Ириклинское водохранилище р. Урал - выше Ириклинского.

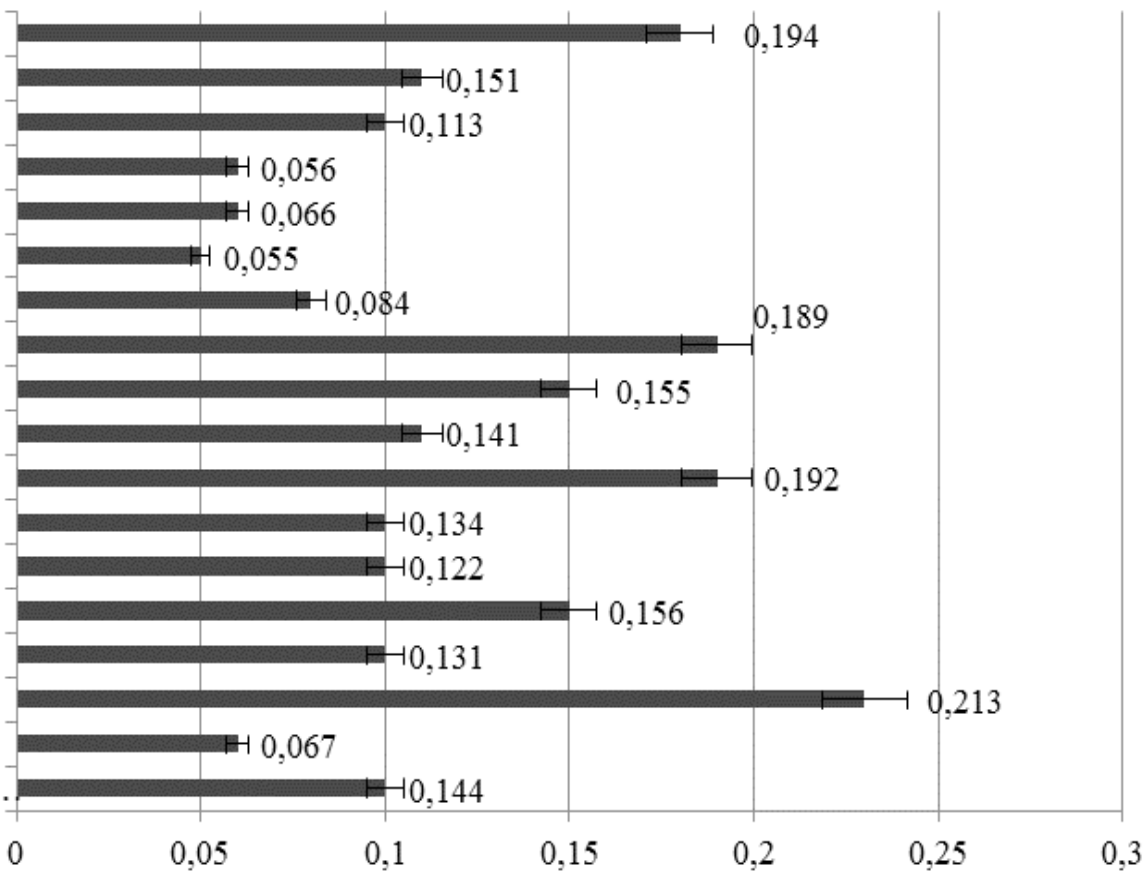

Рис. 1. Валовое содержание кадмия (мг/кг) в илах среднего течения реки Урал (2013 г.)

р. Урал - Чернореченский мост

р. Урал - лагерь "Чайка"

р. Урал - Очистные сооружения p. Урал - Железнодорожный мост

р. Урал - Автодорожный мост р. Урал - Водозабор р. Урал - лагерь "Дубки" p. Урал - Карьер р. Урал - т/б Прогресс р. Урал - с. Красногор р. Урал - с. Алабайтал

р. Урал - с. Никольское р. Урал - ниже г. Новотроицка р. Урал - выше г. Новотроицка р. Урал - в черте г. Орска р. Урал - выше г. Орска р. Урал - Ириклинское водохранилище р. Урал - выше Ириклинского.

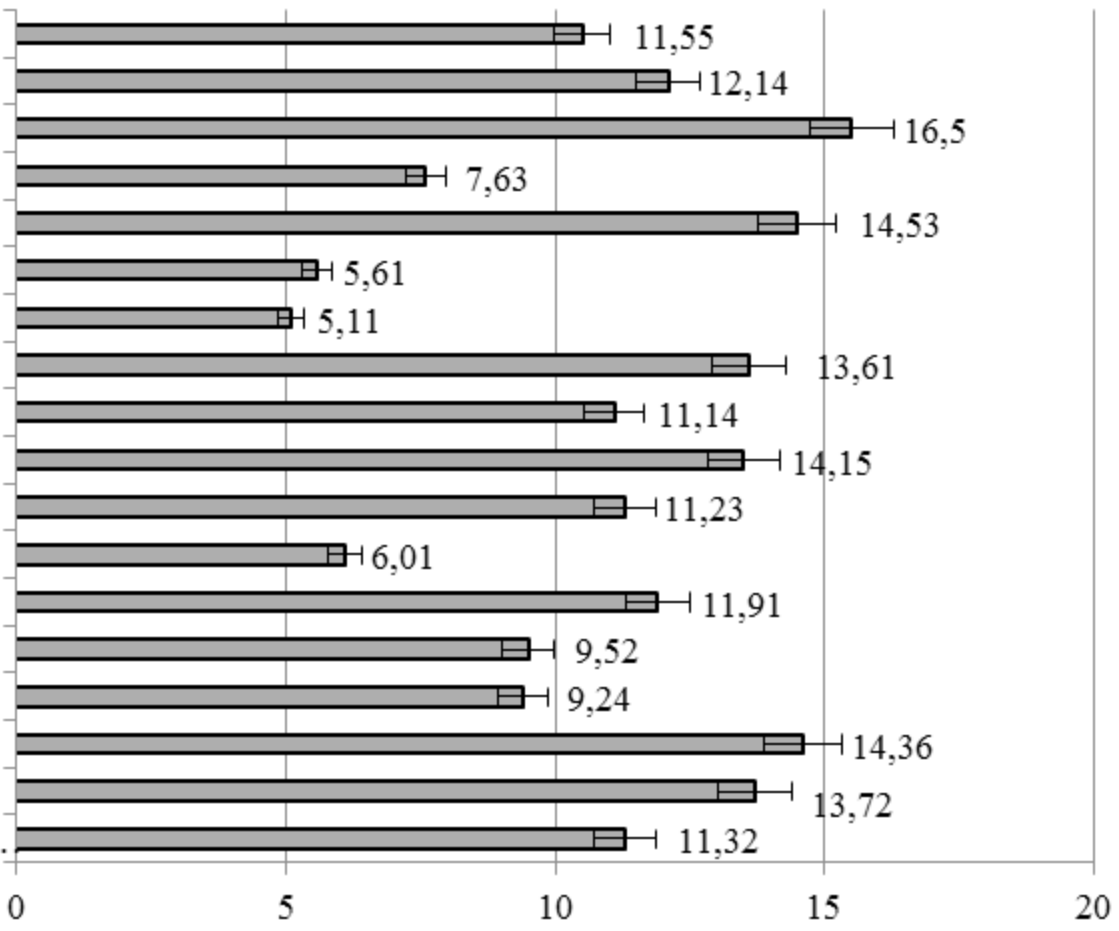

Рис. 2. Валовое содержание свинца (мг/кг) в илах среднего течения реки Урал (2013 г.) 
исследованиями Драбкина Б.С. (1971 г.), Минаковой В.В. (2002-2004 гг.), Голинской Л.В. (2011 г.) в восточных районах области, определили актуальность исследования.

\section{Результаты и обсужление}

Донные отложения (илы) природного пресноводного водоёма формируются из глинистых, суглинистых, песчаных и органических частиц растительного и животного происхождения, непрерывно оседающих на дно в течение длительного периода существования гидробиоценоза [13, с. 95]. Накопление биогенного вещества в донных отложениях, которое происходит как в водоёме, так и на его водосборной площади отражает практически все основные процессы, происходящие в придонных слоях воды, в том числе и накопление тяжелых металлов с течением времени $[14$, с. 70].

Анализ полученных данных показал, что кадмий и свинец присутствуют во всех пробах иловых отложений, отобранных с участков среднего течения реки Урал (рис. 1 и рис. 2). Однако при сравнении значений с экологическим нормативом, составляющим 0,8 мг/кг для кадмия и 86 мг/кг для свинца, превышений по содержанию металлов не установлено. Следовательно, согласно санитарно-гигиеническим нормам в рассматриваемом случае можно считать, что кадмий и свинец в выявленной концентрации ущерба экосистеме не наносят.

Но следует отметить, что по результатам ранее проведённых исследований в 2011 г. кадмий в среднем течение реки Урал вообще не был обнаружен. Следовательно, за прошедший период времени с 2011 г. по 2013 г. кадмий поступал в водоём и аккумулировался в илах большинства исследованных участков. Шесть пунктов на реке Урал следует отметить особо: «туристическая база «Прогресс»», «Чернореченский мост», «выше города Орска», «выше города Новотроицка», «село Алабайтал», «Карьер». По сравнению с остальными участками в иловых отложениях отобранных с данных зон содержание кадмия возросло в 4 раза.

В отличие от кадмия, по результатам ранее проведённых исследований 2011 г. свинец определялся в районе города Орска, что составляло 10,40 мг/кг и в районе города Новотроицка - 14,30 мг/кг [17, с. 76]. В 2013 г. в исследуемых участках средняя концентрация изучаемого металла составила 9,35 мг/кг. Но в пунктах «Ириклинское водохранилище», «выше города Орска», «село Красногор», «Карьер», «Автодорожный мост», «Очистные сооружения» содержание токсиканта в 1,6 раза превысило среднегодовые значения рассматриваемого периода.

Известно, что скорость и характер накопления тяжёлых металлов в иловых отложениях зависит во мно- гом от характера течения реки и структуры илов [7, с. 28]. Показано, что значительное содержание гумусовых кислот, глинистых частиц способствует усилению интенсивности аккумуляции и степени связывания поллютанта в поверхностном слое донных отложений [5, с. 67]. Поэтому далее следует рассмотреть отмеченные участки с позиции характера течения реки и основных горных пород слагающих ее берега и русло. В зависимости от выше указанных особенностей, будет проявляться эффект усиления или ослабления вымывания токсикантов.

Участок выше города Орска (поселок Новоказачий) характеризовался заросшими, сильно заиленными, топкими берегами с ярко выраженной разнообразной болотной растительностью. Донные отложения достигали высоты 25-40 см, были обогащены органическими составляющими преимущественно растительного происхождения. Русло реки представлено большим количеством заводей, течение медленное, глубина значительная около 3-4 м. Участок выше города Новотроицка (село Ущелье) отличался высокими обрывистыми берегами - подмытыми по причине сильного течения, особенно в весенний период. Дно сформировано суглинком, сильно уплотненным галечником и песком, илистых отложений мало, так как, по-видимому, их формирование нарушается сильным течением реки в данной зоне. Участок села Алабайтал также характеризовался очень сильным течением и галечно-песчаным твёрдым дном: иловые отложения практически отсутствовали. На участке туристическая база «Прогресс» отмечена выраженная заиленность прибрежной зоны, большое количество макрофитов и медленное течение. Участок реки Урал в районе пляжа «Карьер»» расположен на 15 км выше города Оренбурга и представляет собой карьер, заполненный водой в период весеннего паводка около 4-х лет назад. Помимо этого рассматриваемая зона находится в стороне от основного русла реки Урал поэтому в ней практически отсутствует течение, обильный рыхлый суглинок, слагающий дно, формирует выраженный слой донных отложений. Участок в районе Чернореченского моста удалён от города на 20 км и расположен ниже по течению реки Урал по направлению к Илекскому району; участок отличается достаточно быстрым течением, наличием небольших прибрежных омутов и заводей со значительным количеством макрофитов на дне и илистым грунтом.

Накопление кадмия на участках выше города Орска (посёлок Новоказачий), туристическая база «Прогресс»», река Урал в районе пляжа «Карьер», в районе Чернореченского моста связано, по-видимому, с повышенной сорбцией токсиканта на частицах суглинка, слагающего илы. Еще одной возможной причиной аккумуляции кадмия и свинца может выступать наличие гумусовых кислот в илах и их активная протекторная 
Таблица 1. Значения коэффициентов обогащения донных (иловых) отложений по кадмию и свинцу

\begin{tabular}{|c|c|c|}
\hline Участки исследования р. Урал & $\begin{array}{l}\left.\text { коэффициент обогащения (КО }{ }_{\text {до }}\right) \\
\text { по кадмию }\end{array}$ & $\begin{array}{l}\text { коэффициент обогащения } \\
\left(\mathrm{KO}_{\partial о}\right) \text { по свинцу }\end{array}$ \\
\hline р. Урал - Чернореченский мост & 1,49 & 72,20 \\
\hline р. Урал — лагерь «Чайка» & 1,16 & 75,90 \\
\hline р. Урал - Очистные сооружения & 0,87 & 103,10 \\
\hline р. Урал - Железнодорожный мост & 0,43 & 47,70 \\
\hline р. Урал - Автодорожный мост & 0,51 & 90,80 \\
\hline р. Урал - Водозабор & 0,42 & 35,10 \\
\hline р. Урал — лагерь «Дубки» & 0,65 & 31,90 \\
\hline р. Урал — «Карьер» & 1,45 & 85,10 \\
\hline р. Урал — туристическая база «Прогресс» & 1,19 & 69,60 \\
\hline р. Урал-с. Красногор & 1,08 & 88,40 \\
\hline р. Урал - с. Алабайтал & 1,47 & 70,20 \\
\hline р. Урал-с. Никольское & 1,03 & 37,60 \\
\hline р. Урал — ниже г. Новотроицка & 0,94 & 74,40 \\
\hline р. Урал — выше г. Новотроицка & 1,20 & 59,50 \\
\hline р. Урал — в черте г. Орска & 1,01 & 57,80 \\
\hline р. Урал - выше г. Орска & 1,64 & 89,80 \\
\hline р. Урал - Ириклинское водохранилище & 0,52 & 85,70 \\
\hline р. Урал - выше Ириклинского водохранилища & 1,11 & 70,70 \\
\hline
\end{tabular}

способность. Протекторная функция указанных соединений проявляется в возможности связывать в прочные комплексы ионы металлов в связи с особенностями химического строения гумусовых кислот. Данные соединения представляют собой нерегулярные сополимеры ароматических оксиполикарбоновых кислот с включением азотсодержащих и углеводных фрагментов, обогащённых карбоксильными (-СООН), гидроксильными (-OH) и метоксильными $\left(-\mathrm{OCH}_{3}\right)$ функциональными группами, обуславливающими их высокую сорбционную способность. Последствия связывания металла с гумусовыми кислотами приводят к изменению формы существования экотоксикантов и уменьшают их биодоступность [16, с. 421].

Накопление металлов в незначительных, вымываемых водой иловых отложениях участков выше города Новотроицка (село Ущелье)» и «реки Урал село Алабайтал» в данном случае маловероятно. Следовательно, кадмий и свинец, возможно, поступали в водоём либо с поверхностным стоком (дождевыми и паводковыми водами, отмечено, что в рудах (халькопирит (CuFeS 2$)$, сфалерит (ZnS) Блявинского месторождения примеси кадмия и Джусинского примеси свинца фиксируются постоянно) $[9,11]$. Либо существовал источник токсикантов, по-видимому, техногенного происхождения, расположенный в непосредственной близости от рассматриваемого района.
Для оценки уровня загрязнённости донных отложений тяжелыми металлами далее рассчитывали коэффициенты обогащения, значения которых приведены в таблице 1.

По значениям коэффициентов обогащения возможно дать ориентировочную сравнительную оценку степени загрязнённости объектов окружающей среды тяжёлыми металлами. В случае рассматриваемых участков среднего течения реки Урал по кадмию наибольший коэффициент обогащения получен для реки Урал - выше города Орска - 1,64. Для свинца в районе очистных сооружений - 103,10, автодорожного моста - 90,80 и на участке выше города Орска - 89,80. Достаточно высокий по сравнению с остальными районами коэффициент обогащения на данных участках еще раз свидетельствует об активных процессах аккумуляции в илах (район очистных сооружений) и, по-видимому, наличии экзогенных источников привнесения металлов.

\section{Зак^ючение}

В пресных водах естественных водоёмов тяжелые металлы существуют, как правило, в разных по активности химических формах и степенях окисления. Для выраженных активных процессов миграции в природных водах значение имеет также окислительно-восстанови- 
тельный потенциал металлов, и, сопутствующие факторы, такие как: кислотно-основные условия (рH) среды, содержание ряда химических компонентов в илах (хлорид-ионы, сульфат-ионы, карбонат-ионы, сульфиды и их концентрации), а также температура и водность года.

Таким образом, результаты исследования содержания кадмия и свинца в иловых отложениях реки Урал показывают:

1. Кадмий и свинец присутствуют в илах всех участков исследования среднего течения реки Урал, что свидетельствует о наличии природных или антропогенных источников различных по подвижности форм данных металлов; однако превы- шений экологического норматива не установлено;

2. Аккумуляция токсикантов в экотопах реки происходит неравномерно, что может быть обусловлено различиями в структуре и свойствах иловых отложений (присутствие глинистых частиц, протекторная способность гуминовых кислот), характере и скорости течения реки, неравномерности её среднегодового стока;

3. Значения коэффициента обогащения по кадмию и свинцу достаточно чётко иллюстрируют участки, имеющие наибольший уровень загрязнения данными поллютантами: для кадмия река Урал выше города Орска, для свинца очистные сооружения города Оренбурга.

\section{ЛИТЕРАТУРА}

1. Аксентов К. И. Скорости аккумуляции ртути в донных осадках Амурского залива (Японского моря) / К. И. Аксентов, А. С. Астахов, И. А. Калугин // Сборник трудов Второго международного симпозиума Ртуть в биосфере: эколого-геохимические аспекты. - 2015.— С. 14-18.

2. Ашихмина Т. Я. Аккумуляция ртути растениями из техногенно-нарушенных почв в пойме р. Вятки / Т. Я. Ашихмина, С. Г. Скугорева // Сборник трудов Второго международного симпозиума «Ртуть в биосфере: эколого-геохимические аспекты». — 2015. — C. 35-37.

3. Белеванцев В. И. Подход к химико-термодинамическому анализу состояний тяжёлых металлов в окружающей среде (на примере ртути) / В. И. Белеванцев, А. П. Рыжих // Сборник трудов Второго международного симпозиума «Ртуть в биосфере: эколого-геохимические аспекты».— 2015.— С. 38-42.

4. Болтунова А.Д., Смирнова С. В., Солтис В. В. Накопление тяжелых металлов в почвах под влиянием промышленного производства // Современные проблемы науки и образования. 2017. № 4.; URL: http://www.science-education.ru/ru/article/view?id=26637 (дата обращения: 04.01.2020).

5. Даувальтер В.А., Кашулин Н. А. Тяжелые металлы в донных отложениях озер центральной и юго-западной частей Мурманской области. - Вестник Кольского Научного Центра РАН.— № 3(26). - 2016. - С. 73-87.

6. Кокин А. В. Влияние окружающей среды на подвижность тяжёлых металлов в растениях в условиях лесомелиоративных систем // Российская сельскохозяйственная наука. — 2016. — № 5.- С. 74-77.

7. Мирошникова Е.П., Аринжанов А.Е. Тяжелые металлы в воде и донных отложениях Ириклинского водохранилища - Вестник 0ГУ.— 2016. (194).- - C. 70-73.

8. Рувинова Л.Г., Сверчкова А.Н., Хамитова С. М., Авдеев Ю. М. Биологический мониторинг загрязнения почвенной и водной среды в условиях урбанизации // Вестник Красноярского государственного аграрного университета.— 2016.— № 6 (117). — C. 14-20.

9. Сивохип Ж. Т. Эколого-гидрологическая специфика территории как фактор лимитирующий природопользование в степной зоне (на примере бассейна р. Урал / Ж. Т. Сивохип // Бюллетень Оренбургского научного центра Ур0 РАН.— № 13(188). — 2015.— С. 203-208.

10. Томилина И.И. Биологические эффекты действия загрязняющих донные отложения водоёмов центрального и южного Вьетнама на гидробионтов / И. И. Томилина, Л. П. Гребенюк, Н. В. Лобус, В. Т. Комов // Биология внутренних вод. — № 4. - 2016. — C. 78-87.

11. Явербаум П. М. Общие вопросы токсического действия свинца / П. М. Явербаум. — Иркутск. - 2006.— 344 с.

12. Ci Z.J. Elemental mercury $(\mathrm{Hg}(0))$ in air and surface waters of the Yellow Sea during late spring and late fall 2012: Concentration, spatial-temporal distribution and air/sea flux / Z. J. Ci, C. J. Wang, Z. W. Wang, X. S. Zhang // Chemosphere. - 2015.—V. 119. — P. 199-208.

13. J. Bieser. Multi-model assessment of mercury cycling in the atmosphere as a part of GMOS mercury modeling task force / J. Bieser, A. Dastoor, C. Friedman, I. M. Hedgecock, V. Matthias, A. Ryzhkov, N. Selin, F. De Simone, S. Song // Abstracts of 12th International Conference on Mercury as a Global Pollutant. Jeju Korea. 2015.-P. 101.

14. Sheehan, M. C. Global methylmercury exposure from seafood consumption and risk of developmental neurotoxicity: a systematic review / M. C. Sheehan, T. A. Burke, A. Navas-Acien, P. N. Breysse, J. McGready, M. A. Fox // Bull. World Health Organ. — 2014. — Vol. 92. — P. 254-269.

15. Dietz, R. What are the toxicological effects of mercury in Arctic biota? / R. Dietz, C. Sonne, N. Basu et al. // Sci. Total. Environ. — 2013.—Vol. 443.—P. 775-790.

16. Wu, R. S. Hypoxia: from molecular responses to ecosystem responses / R. S. Wu // Marine Pollution Bulletin. — 2002. — V. 45. — P. 35-45.

17. Smaoui-Damak, W. In situ potential use of metallothionein as a biomarker of cadmium contamination in Ruditapes decussates / W. Smaoui-Damak [et. al.] // Ecotoxicol Environ Saf. — 2009.— Vol.— 72.— № 5.—P. 1489-1498.

\footnotetext{
(c) Соловых Галина Николаевна ( k_biology@orgma.ru ), Шостак Елена Ивановна,

Осинкина Татьяна Владимировна ( osinkina12@mail.ru ).

Журнал «Современная наука: актуальные проблемы теории и практики»
} 